University of Nebraska - Lincoln

DigitalCommons@University of Nebraska - Lincoln

Faculty Publications, Department of Psychology

Psychology, Department of

September 2005

\title{
The role of adult expectations on the recovery of sexually abused children
}

Haig Kouyoumdjian

University of Nebraska-Lincoln

Andrea R. Perry

University of Nebraska-Lincoln

David J. Hansen

Univertsity of Nebraska-Lincoln, dhansen1@unl.edu

Follow this and additional works at: https://digitalcommons.unl.edu/psychfacpub

Part of the Psychiatry and Psychology Commons

Kouyoumdjian, Haig; Perry, Andrea R.; and Hansen, David J., "The role of adult expectations on the recovery of sexually abused children" (2005). Faculty Publications, Department of Psychology. 5. https://digitalcommons.unl.edu/psychfacpub/5

This Article is brought to you for free and open access by the Psychology, Department of at DigitalCommons@University of Nebraska - Lincoln. It has been accepted for inclusion in Faculty Publications, Department of Psychology by an authorized administrator of DigitalCommons@University of Nebraska - Lincoln. 
Aggression

And

Violent

Behavior

\title{
The role of adult expectations on the recovery of sexually abused children
}

\author{
Haig Kouyoumdjian* \\ Andrea R. Perry \\ David J. Hansen
}

\begin{abstract}
Child sexual abuse is a disturbingly prevalent problem that has continued to receive increased attention in the United States. Because there is substantial variability in how sexual abuse impacts children, it is important to examine potential mediating variables, including the ways in which child and family factors contribute to children's recovery. One of the most extensively researched family variables has been parental support, and this research has demonstrated a positive relationship between parental support and children's functioning following sexual abuse. Another family variable that likely influences parent-child interactions and children's recovery is parental expectations. Although adults' expectations about children who are disadvantaged, gifted, or from varying family structures have been shown to influence children's functioning, research has only begun to examine the impact of adults' expectations on children's adjustment from sexual abuse. In light of the consistent finding that adults, including parents, teachers, and professionals, appear to hold negative expectations about the outcomes of sexually abused children, it is important to systematically investigate the relationship between parental expectancies and children's recovery from sexual abuse. Recommendations for future research and intervention are provided in an effort to better understand the role of adult expectations on the recovery of sexually abused children.
\end{abstract}

Keywords: sexual abuse; labeling; expectancies; expectations; recovery

* Corresponding author. Tel.: +1 402472 3721; fax: +1 402472 4637. E-mail address: hkouyoum@unlserve.unl. edu (H. Kouyoumdjian). Department of Psychology, University of Nebraska-Lincoln, 238 Burnett Hall, Lincoln, NE 68588-0308, United States

Published in Aggression and Violent Behavior 10 (2005), pp. 475-489; doi:10.1016/j.avb.2004.07.002 . Copyright (C) 2004 Elsevier Ltd All rights reserved. Received 6 October 2003; revised 14 June 2004; accepted 26 July 2004. Available online 21 September 2004. http://www.elsevier.com/wps/find/journaldescription.cws home/30843/ description\#description 


\section{Contents}

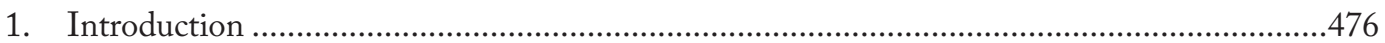

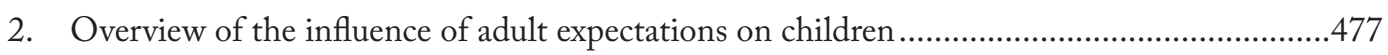

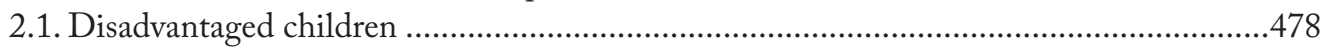

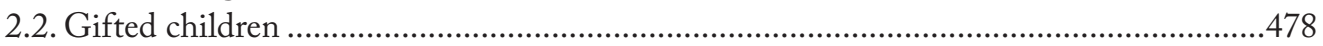

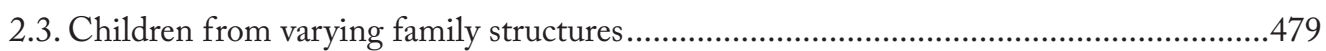

3. The impact of adults' expectations on sexually abused children .............................................479

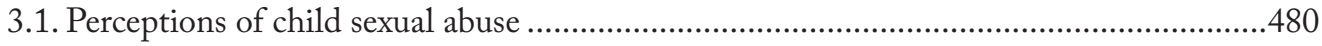

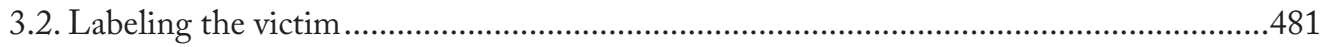

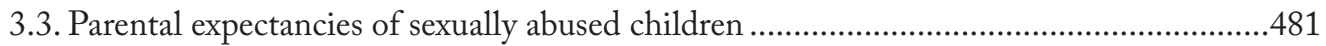

3.4. Teachers' expectancies of sexually abused children ........................................................482

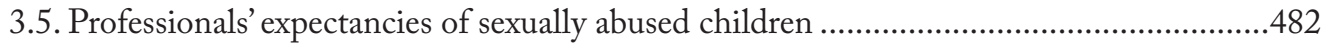

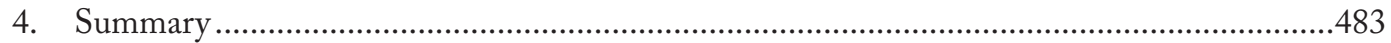

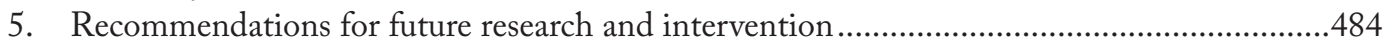

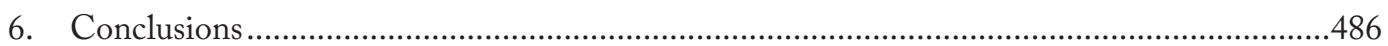

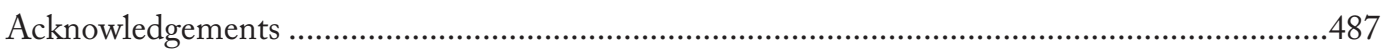

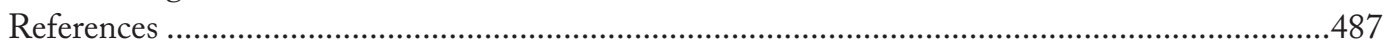

\section{Introduction}

Although estimates of child sexual abuse are influenced by methodological (e.g., measurement techniques, reporting issues) and conceptual (i.e., numerous operational definitions of child sexual abuse) variations, research in the past several decades has established that child sexual abuse is a prevalent societal phenomenon (e.g., Gorey \& Leslie, 1997 and United States Department of Health and Human Services, 2004). Within the child sexual abuse literature, a variety of short-term and long-term consequences have been documented, including internalizing and externalizing symptoms (e.g., Bauserman \& Rind, 1997, Jumper, 1995 and Rind \& Tromovitch, 1997). To better understand the development of these deleterious outcomes, research has examined many factors that may be involved in determining the impact of sexual abuse on children. One such area that has received significant research attention is how family variables (e.g., parental support) may influence children's recovery. Although a tremendous amount of information has been gleaned from these studies, a related and potentially influential family variable that has been largely overlooked is the role of parental expectations on children's recovery. Because there is already well-documented support in the social psychology research literature demonstrating the impact of adult expectations on selective groups of children (e.g., disadvantaged, gifted), it is reasonable to expect that adult expectations have an influence on sexually abused children as well. Because this area of research is limited, the purpose of this paper is to provide substantial support for the careful research consideration of the influence of adult expectations on the recovery of sexually abused children. Only with such research will we be able to better understand how poor expectations may increase the likelihood of deleterious outcomes in sexually abused children.

This paper reviews research that identifies adults' expectations for various groups of children (e.g., children from varying family structures, gifted children), including those who 
have been sexually abused, as well as research exploring the possible impact these expectations have on children's functioning. As part of this objective, a review of empirical literature on the perceptions that parents, teachers, and professionals have on child sexual abuse is included. Directions for future research and intervention on adult expectations of sexual abuse are also discussed.

\section{Overview of the influence of adult expectations on children}

Social psychologists have extensively researched the reciprocal relationship between interpersonal expectations and the development of stereotypes and labels. Within this research, interpersonal expectations have been shown to develop when people cognitively organize their perceptions of others to form stereotypes (Schwanenflugel, Guth, \& Bjorklund, 1986). As such, formation of these stereotypes may ultimately result in the labeling of others based on their behaviors. In fact, after a label has been assigned, individuals' expectancies for the behavior of the labeled person are often formed in a way that is congruent with the label. This can, in turn, lead to people having lower expectations of others' behaviors and may function as a self-fulfilling prophecy (Rosenthal \& Jacobson, 1968).

One well-researched area of how labels can affect children's functioning comes from studies examining teacher-student interactions. Rosenthal \& Jacobson, 1966 and Rosenthal \& Jacobson, 1968, for example, conducted a classic research study on the influence of teacher expectations on elementary students' achievement. In this study, a standardized intelligence test (composed of items measuring verbal and reasoning skills) was administered to each first- through sixth-grade student at an elementary school. Based on random assignment rather than the actual testing results, Rosenthal and Jacobson gave teachers a list of children (20\%) who were identified as having the potential for substantial academic growth (i.e., "blooming") during the following school year. Eight months later, the authors gave all elementary students the same standardized intelligence battery. Overall, they found strong evidence for the impact of self-fulfilling prophecies in a classroom environment. Specifically, teachers' expectations for students' achievement were found to influence students' performance in a manner that fulfilled the teacher's expectations. Students who were identified to teachers as possessing the potential to "bloom" scored significantly higher on the IQ test than the other students, particularly for younger children (Rosenthal \& Jacobson, 1966 and Rosenthal \& Jacobson, 1968). Results of many other experimental and naturalistic studies also show strong support for self-fulfilling prophecies occurring in the teacher-student relationship (see Jussim \& Eccles, 1995 and Rosenthal \& Rubin, 1978 for reviews). Teachers' low expectations appear to produce a classroom environment that encourages students to live up to the low and often erroneous expectations placed upon them. Moreover, teachers may influence students' educational achievement by changing students' self-concepts, which is a common outcome of self-fulfilling prophecies (see Darley \& Fazio, 1980 and Deaux \& Major, 1987 for reviews).

Since Rosenthal and Jacobson's (1968) classic study demonstrating that teacher expectations impact students' achievement, much research about the influence of adult expectations on children has taken place. This research has focused on various groups of children, 
including those who are disadvantaged and gifted, as well as those from varying types of family structures. A brief overview of the major findings in each of these areas will be provided before examining adults' expectations of sexually abused children and how these expectations may potentially influence children.

\subsection{Disadvantaged children}

Many adults endorse negative expectancies about children who exhibit certain characteristics, such as being disadvantaged (e.g., brain injured, mentally retarded). An example of how these expectations can inhibit children's development is found among mothers of brain-injured children who reported having somewhat lower achievement expectancies than mothers of children without history of brain injury. Highlighting the strong influence of parental expectancies on children, not only did parents have decreased expectations for their minimally brain-injured children, but the children also reported lower achievement expectations for themselves (Touliatos \& Lindholm, 1974). In addition to parental expectancies, Vance and Wallbrown (1979) conducted a review of studies examining the relationship between teachers' perceptions of children with learning disabilities and the actual behavior of these children. Overall, this review found that the label of "learning disabled" seems to strongly influence teachers' expectations and interpretations of children's actual behavior. For instance, children with learning disabilities exhibited many positive behaviors in the classroom that were not reinforced by the teacher. Examples of these behaviors included looking reasonably busy, trying to not get in trouble or cause a disruption, and engaging in social interactions with similar frequency as peers in a comparison group. The negative consequences of labeling a child as learning disabled also include greater peer rejection (Bryan \& Perlmutter, 1979) and reduced levels of interaction with parents (Freund, Bradley, \& Caldwell, 1979).

\subsection{Gifted children}

As one might expect, there has been less research interest in examining the effects of positive labels on children compared to examining the effects of negative labels. The available research with children suggests that the use of positive labels, such as "giftedness," can have some potentially adverse effects on their development. For instance, Cornell (1989) examined parents' perceptions and labels of their gifted child ( $N=424$ mothers and $317 \mathrm{fa}-$ thers) as well as the child's reports of self-concept, anxiety, and peer status ( $\mathrm{N}=482$ children). He found that children whose parents referred to their gifted children as "gifted" had more negative self-concepts, higher anxiety levels, and lower peer status than did children whose parents did not use the term "gifted." This study was especially informative because it distinguished between using the term "gifted" and thinking of a child as being gifted. Additional adjustment difficulties experienced by gifted children whose parents use the term "gifted" are poor self-control, guilt, and somatic problems (Cornell \& Grossberg, 1989). Cornell's findings suggest that parents who overemphasize the gifted label may be limiting the optimum development of their child, and may even adversely affect the child's 
social and emotional adjustment if their expectations are too high. As a result, parents may credit their children with excessive competence, which may potentially result in a decreased likelihood that parents will attend to their children's needs.

\subsection{Children from varying family structures}

Research has revealed that many people have stereotypes about family structure. Consequently, the use of these stereotypes can have adverse effects on children. For instance, although attitudes toward divorce have become more accepting over time, some people believe that divorce leads to a more negative perspective on marriage and family life and that it has a negative impact on children (Burgoyne \& Hames, 2002). In addition, it is commonly assumed that, compared to the two-parent family, the single-parent family is less than ideal for the socialization of children (Thornton, 1985). Teachers, for example, have been shown to have more negative expectancies in the areas of academic, social, and emotional functioning of children from divorced families than children from intact families (Ball et al., 1984 and Guttman \& Broudo, 1989). Additionally, Amato (1991) found adults to report predominantly negative views of children from divorced families in relation to their behavioral (e.g., disruptive, rebellious) and social (e.g., unpopular, prone to divorce later in life) characteristics, and mixed views in relation to their psychological attributes (e.g., distrustful, responsible). Consistent with perceptions on children of divorced parents, members of stepfamilies have been reported to receive more negative stereotypes than other family structures (Bryan, Coleman, Ganong, \& Bryan, 1986). In fact, adults more negatively perceive a child labeled as "stepchild" than a child from an intact, divorced, widowed, or never-married family. Although there is some empirical support for stepfamilies providing healthy home environments for children (Kelley, 1995), it appears as though adults' expectations of children from these families are generally accurate. Specifically, research shows children in stepfamilies to be more susceptible to a variety of problems, including poor school performance and greater behavior problems (Demo \& Acock, 1996 and Zill, 1988). In general, it appears that adults expect children from nonintact families to have a variety of adjustment and developmental problems. Such beliefs can influence adults to treat these children in ways that maintain and potentially even foster poor cognitive, social, and psychological functioning, which in turn can lead to the occurrence of self-fulfilling prophecies.

\section{The impact of adults' expectations on sexually abused children}

As can be seen, previous research has illustrated that children's functioning can be profoundly impacted by adults' expectations. Similarly, an emerging body of research has demonstrated that individuals who experience child sexual abuse seem to be influenced simultaneously by adults' perceptions of the abuse as well as by adults' expectancies of the outcome. Research examining adults' expectancies will be discussed in depth. First, it is important to briefly consider the ways in which adults define and interpret child sexual abuse. 


\subsection{Perceptions of child sexual abuse}

Perhaps the most common methodological approach for measuring perceptions of child sexual abuse is the use of analog studies, which involves presenting participants with sexual abuse vignettes and having them rate aspects of the scenario. Although criticized for their limited generalizability, these studies provide valuable insight into how child sexual abuse encounters are perceived. Within this literature, researchers have examined perceptions of sexual abuse by manipulating various characteristics of the vignette, such as the age of the victim (e.g., Maynard \& Wiederman, 1997), the age of the perpetrator (e.g., Fromuth, Holt, \& Parker, 2001), and the gender amalgam of the vignette (e.g., Smith, Fromuth, \& Morris, 1997). For example, Maynard and Wiederman (1997) found that sexual experiences were viewed as more abusive when involving younger children (i.e., 7-yearolds versus 15-year-olds) and same-gender interactions. Additionally, in an examination of high school teacher/student sexual experiences, Fromuth et al. (2001) found that the female teacher/male student dyad was given more positive ratings (e.g., fewer "psychological problems for students") than the male teacher/female student scenario. Furthermore, men were more likely than women to rate the sexual relationship as a "positive sexual experience." Conversely, women tended to view the scenarios more negatively, as evidenced by elevated ratings of teacher responsibility and years of incarceration warranted. When extending this research to include cross- and same-gender dyads, Dollar, Perry, Fromuth, and Holt (2004) found, for example, that same-gender scenarios were more likely to elicit perceptions of sexual harm than cross-gender scenarios. When assessing for the "normalcy" of the experience (e.g., "Student will brag to friends") and potential psychological ramifications (e.g., "Student will be very upset"), the male teacher/male student dyad was consistently rated as the most damaging, whereas the female teacher/male student scenario was rated as the least aversive.

A comprehensive study conducted by Broussard, Wagner, and Kazelskis (1991) further illuminates the ways in which undergraduate students perceive child sexual abuse. Specifically, written descriptions of sexual interactions between an adult and a 15-year-old were presented to 180 male and 180 female undergraduates to investigate the impact of victim sex, perpetrator sex, respondent sex, and victim response on labeling of child sexual abuse, effect on the child, and perception of realistic victim behavior. Results indicated that male offenders were viewed as more harmful to male victims and female offenders more harmful to female victims when children responded in an encouraging manner. In addition, when a female offended a male, college students expected passive and encouraging male victims to be less negatively impacted than resisting males. Additionally, college students rated the male victim and female offender interaction to be less representative of sexual abuse. Taken together, research on perceptions of child sexual abuse highlights the ways in which individuals define and interpret sexual encounters between adults and children/adolescents. It is likely that these perceptions also influence adults' labeling of, and expectancies about, children who have been sexually abused. 


\subsection{Labeling the victim}

Labeling, whether utilized for classifying psychiatric diagnoses or for defining a status, such as "victim" or "perpetrator," often successfully allows professionals to identify and communicate with others about specific problems, make appropriate referrals, and gain access to available treatment services. Despite these benefits, research has found that placing the label of "victim" on an individual may also have deleterious consequences. In particular, because children who are sexually abused commonly experience a variety of significant adverse psychological, emotional, and behavioral effects, adults may label the child as a "sexual abuse victim" and consequently associate the labeled child with negative expectancies. Although such a reference may be accurate with children's experiences, the label itself implies negative assumptions that can adversely affect children (Holguin \& Hansen, 2003). Given literature that suggests parents' expectations of their children's behavior can influence the quality of family relationships (e.g., Azar \& Wolfe, 1998 and Bugental et al., 1998), it is important to consider the effects of the "sexually abused" label on parents' expectations of their child. The intention of examining the impact of labeling on parents' expectations is not to blame parents, but rather to gain a more thorough understanding of the labeling effects. After all, it would not be fair to blame parents because, as previously demonstrated, the perceptions people have about individuals with sexual abuse histories often stem from prevalent attitudes in society (Broussard et al., 1991 and Podell et al., 1994).

\subsection{Parental expectancies of sexually abused children}

Research examining adult expectations about child sexual abuse highlights the ways in which parents may perceive, and consequently may respond to, their sexually abused children. Within this research, adults have been reported to view children with a history of sexual abuse as less likely to achieve and to have friends, and more likely to demonstrate aggressive behaviors and to have internalizing behavior problems than children without such a history (Briggs, Hubbs-Tait, Culp, \& Morse, 1994). The strength of adults' negative expectations for sexually abused children is particularly revealing in a study that compared adult bias in expectancies for three groups of children: sexually abused children, children from normal families, and children who had mothers with terminal cancer (Briggs, Hubbs-Tait, Culp, \& Blankemeyer, 1995). In this study, a matched subset of 67 male and 67 female undergraduate students was asked to respond to a vignette portraying an aggressive act by a 6-year-old child on a playground, with the intensity of aggression, child status (i.e., sexual abuse recipient, normal, mother dying of cancer), and the child's gender being varied, resulting in 12 respective vignettes. This study found that children with a history of sexual abuse were perceived as having the most internalizing and externalizing behavior problems. An additional finding is that children with a history of sexual abuse who demonstrated less aggressive behavior than children in the other groups were perceived as having greater internalizing, but not externalizing, problems. This finding is particularly salient because it demonstrated that there are many negative perceptions associated with the "sexual abuse" 
label. The results of these studies warrant investigating the expectations for sexually abused children held by different groups of adults, such as teachers, mental health professionals, and law enforcement personnel.

\subsection{Teachers' expectancies of sexually abused children}

Bromfield, Bromfield, and Weiss (1988) examined the influence of child sexual abuse history on teachers' perceptions of children's academic performance. Two identical vignettes of a 6-year-old girl having difficulties assembling a puzzle and eventually giving up were presented to junior high and high school teachers. The only difference between the two vignettes was that one included a statement that described the girl as having been sexually abused. This study revealed that, although teachers rated the sexually abused child as superiorly skilled, they perceived these children to be more vulnerable to academic stress and more likely to achieve less future success. Other research has shown teachers to expect more future psychopathology in sexually abused children (O'Donohue \& O'Hare, 1997). These findings suggest that labeling effects influence even teachers' expectations of children who have been sexually abused.

\subsection{Professionals' expectancies of sexually abused children}

Not only do labels influence parents' and teachers' expectations, but they also can impact the judgment of mental health professionals (Langer \& Abelson, 1974). For example, DeRoma, Hansen, Tishelman, and D'Amico (1997) examined the influence of information related to physical maltreatment on professionals' ratings of adjustment and prognosis. This study presented written case vignettes to 20 child protective service employees and 20 clinical psychology graduate students and professors, all of whom are expected to be able to make judgments about maltreated children. Although presence of abuse history was influential for clinical psychology and child protective service participants, it was the most significant for child protective service employees. When all content factors of the vignettes other than maltreatment status were held constant (e.g., child gender, presence/absence of behavior problems), child protective service employees rated children who had experienced abuse to have poorer adjustment and to be more in need of treatment. Additionally, in a study that examined psychologists' attitudes about child sexual abuse, 303 American Psychological Association members responded to a child sexual abuse scenario involving an 11- or 15-year-old girl and a 35-year-old man (Wagner, Aucoin, \& Johnson, 1993). Results demonstrated that $46 \%$ of the psychologists attributed low blame to the child/adolescent and high responsibility to the adult. However, psychologists' perceptions of the vignette were somewhat impacted by the child's response (e.g., encouraging) during the sexual experience. Finally, Hetherton and Beardsall (1988) examined the effects of perpetrator gender on the perceptions of professionals (i.e., social workers and police officers) who work directly with sexually abused children. In this study, participants were presented with a vignette that depicted a child sexual abuse experience and a subsequent allegation. Across all scenarios, male-perpetrated abuse was rated as warranting greater sanctions (e.g., imprisonment) than 
was female-perpetrated abuse. The results from these studies suggest that mental health professionals and other professionals who work with sexually abused children are also at risk for having their perceptions influenced by abuse characteristics, such as the abuse label, the child's response, and the gender of the perpetrator.

Other research has used vignettes to focus specifically on how the sexual abuse label may influence the perceptions of professionals from varying disciplines. In a recent study conducted by Holm, Holguin, and Hansen (2002), 309 professionals (e.g., mental health providers, law enforcement, legal profession, Child Protective Services personnel) rated a vignette about a child that was only varied by the type of presenting stressor (sexual abuse, parental divorce, or a recent loss of sleep). No information regarding frequency, duration, level of intensity, or other qualitative aspects of the stressor were provided in an effort to allow the participants to interpret the content of the vignette with whatever perceiver bias they may develop. The major finding of this study was that professionals rated the children with a sexual abuse label as having greater difficulty in several areas of functioning, such as academic functioning (e.g., school performance, motivation), social/interpersonal functioning (e.g., making new friends, ability to communicate feelings), emotional functioning (e.g., depression, anxiety), behavioral functioning (e.g., following rules at home and school, fighting with peers), and risk-taking behaviors (e.g., alcohol or drug use). Findings from this study suggest that many professionals who work with sexually abused children may be susceptible to labeling effects when making clinical judgments such that they may have lowered expectations about the future development and adjustment of sexually abused children.

\section{Summary}

Just as adults have been shown to label and form expectations of children based on characteristics, such as intelligence and family background, it seems that adults, including parents, mental-health professionals, and teachers, also apply negative stereotypes to children and adolescents who have been sexually abused. Considering the sexual abuse label specifically, research strongly suggests that adults perceive children with a history of sexual abuse more negatively than their nonabused peers. As such, these negative perceptions may influence adults to engage in harmful interactions (e.g., less supportiveness; conveyance of lowered expectations) with sexually abused children. The above findings are especially troubling when considered in light of the many children with histories of sexual abuse who are not noticeably affected by the experience. It is likely that adults are applying and reacting to the label of "sexually abused child" even if the child is not exhibiting any adverse effects of sexual abuse. These negative expectations about children with sexual abuse histories could potentially interfere with children's resilience and consequently promote adverse effects in some asymptomatic children (Briggs et al., 1994).

Although adults' expectations of sexually abused children are important, there are no current studies that specifically examine the impact of negative expectations on the recovery of sexually abused children. Because adults' negative expectations can foster poor 
interactions with children, further research is urgently needed in order to (a) examine how adults' expectancies of sexually abused children impact their interactions with these children, and to (b) explore the impact of adults' expectations on children's recovery from sexual abuse. Clearly, there are tremendous methodological challenges in conducting such research. However, because there is well-established literature showing that adults' expectations of children can influence both their interactions with children and children's behaviors and emotions (e.g., Cornell, 1989, Rosenthal \& Jacobson, 1968 and Touliatos \& Lindholm, 1974), future researchers are strongly encouraged to begin addressing the challenges of studying the role of parental expectations on the functioning and recovery of sexually abused children.

\section{Recommendations for future research and intervention}

Understanding the predictive relationship between adults' knowledge about child sexual abuse (e.g., prevalence, variability in children's resulting symptomatology, abuse characteristics) and their expectations of children's functioning not only will contribute to existing knowledge of how adult expectations develop but also will ultimately have important clinical implications. Given that parents' expectancies of their children can influence how they interact with them, parental expectations may function as a predictor of supportive parenting behavior. For example, parents who have higher expectancies may provide their child with more advanced opportunities for growth, whereas parents who have lower expectancies may be less likely to present challenging activities. This research focus is particularly important because published reports suggest that adults associate negative expectations with children who have been sexually abused (e.g., Briggs et al., 1995) and that negative expectations can potentially lead to self-fulfilling prophecies (Rosenthal \& Jacobson, 1968). Although prior research has contributed greatly to understanding the effects of the sexual abuse label on adults' expectations of child victims, further research examining the relationship between adult expectations and children's recovery from sexual abuse is warranted. Such research is encouraged to manipulate and control for variables that are known to be associated with the impact of sexual abuse on children (e.g., children's age, severity of abuse, relationship to offender, use of threat). Learning more about how adult expectations develop and how they impact the functioning of sexually abused children can be beneficial in the development of more effective treatment interventions for children and their families.

Much of the existing research on the relationship between adult expectations and children's functioning has been with college students and these studies have serious limitations in external validity. In an effort to strengthen our understanding of how sexual abuse is perceived by adults, future research is encouraged to replicate prior studies on expectancies for sexually abused children that have utilized college student samples by using samples which could reveal more clinically relevant results (e.g., parents). Because parents usually interact closely with their children and parental support has been shown to be a key variable in children's adjustment from sexual abuse, progress in this area of research will have important implications for intervention. Additionally, due to the 
important role parental variables have in children's recovery from sexual abuse, psychological intervention for the treatment of child sexual abuse should not be limited to the child victim, but should also include parents (Waterman \& Kelly, 1993). In fact, many forms of clinical intervention already provide training for parents and other caregivers to help them interact with their children in supportive and nonpunitive ways (e.g., Hansen, Hecht, \& Futa, 1998). It is important to continue these efforts to help children recover successfully from sexual abuse (Deblinger, Lippmann, \& Steer, 1996). Of course, these interventions should be sensitive to developmental issues, such as the necessary balancing of adolescents' need for autonomy and the need for parents to monitor adolescents' social activities (Feiring \& Lewis, 1993).

Teachers not only spend a considerable amount of time working and interacting with children, but teachers' expectations of sexually abused children also have been found to influence children's behavior and performance. As a result, research that examines the impact of teachers' expectancies on sexually abused children's outcomes is warranted. Furthermore, it is recommended that future research seeks to determine the extent to which sexual abuse directly results in academic and psychological problems. It is also important to explore the extent to which teachers' knowledge of children's sexual abuse history mediates this relationship (O'Donohue \& O'Hare, 1997). Although this research agenda is challenging to accomplish, it can be carried out by longitudinal studies that compare the academic outcomes of sexually abused children with teachers who are aware of the abuse and with teachers who are not aware of the abuse. Such research would have to control for extraneous variables, such as severity and disruptiveness of the abuse (O'Donohue \& O'Hare, 1997).

Parents and teachers are not the only individuals who have been found to impact sexually abused children's recovery. In fact, current research suggests that even helping professionals may possess negative expectancies about sexually abused children. Consequently, they may have difficulty perceiving these children as resilient, socially competent, and responsible for their own behaviors (Briggs et al., 1994). However, this may be partially reflective of the notion that mental health professionals interact with sexually abused children in ways that bias their assessment of these children and the treatment services they provide (Briggs et al., 1994). Helping professionals who are aware of their own expectations of sexually abused children, the expectations held by caregivers, and the adverse consequences negative expectations can have on children's functioning, are in a position to help caregivers develop less negative expectations and interact with children in ways that promote optimal development.

In hopes of providing a nurturing environment for children's recovery, all professionals who come in contact with sexually abused children, such as law enforcement personnel and mental health care providers, should be made aware that their expectations can influence how they perceive indicators of sexual abuse (Kendall-Tackett \& Watson, 1991) and that labeling can lead to more negative expectancies of children's functioning. When professionals become increasingly aware of any biased expectations they may have (e.g., expectations based on child's age, severity of abuse, child's relationship with the offender, family environment), they can obtain more accurate assessment information and be more attentive to each child's unique experiences. Adults who interact closely with sexually 
abused children also should be informed about the broad range of outcomes that are possible for these children, including the possibility of children not presenting with impairment in functioning. It is important for all professionals to accept responsibility for informing caregivers, colleagues, and other professionals about how expectations can impact not only adult/ child interactions, but also children's well being. As a result of these collaborative efforts, improvement in children's adjustment following sexual abuse may increase substantially.

\section{Conclusions}

Despite heightened empirical research and public awareness, child sexual abuse continues to remain a disturbing societal problem. Because outcomes of sexual abuse vary significantly among children, researchers have examined the impact of child, family, and abuse characteristics on the development of symptomatology in children. Related research provides strong evidence for parental support having an influence on children's recovery. Although research examining various aspects of parental support (e.g., belief in child, attention given to child, attitude toward getting help for the child) has been valuable, an area of family background that has been neglected and will be influential in children's recovery from sexual abuse is parental expectations. Because there is often stigma associated with child sexual abuse, and because adults' negative expectations of children's functioning are associated with adverse outcomes in children, the negative expectations are likely contributing to some of the adverse effects found in many sexually abused children. These expectations may act to maintain and/ or exacerbate the development of symptomatology in sexually abused children. There is no denying the fact that child sexual abuse can potentially lead to serious adverse consequences. The intent here is to suggest that the negative expectations held by adults can influence how they interact with sexually abused children and that the sexual abuse label may act to maintain or exacerbate adverse outcomes of child sexual abuse.

Future research should ascertain how adults' expectations about sexually abused children develop. Additionally, it is important to examine the extent to which negative expectations held by various groups of adults (e.g., parents, teachers, mental health professionals, law enforcement personnel, medical doctors) influence the development of symptomatology in children in ways that supersede any deleterious effects caused by the actual abuse. Knowledge about such outcomes, and even simply the awareness that negative expectations may adversely impact children's adjustment from sexual abuse, can help to enhance the interactions peo-

ple have with sexually abused children. With the advent of further research on the impact of adults' expectations on children's recovery from sexual abuse, as well as with the effective dissemination of research findings, mental health professionals should be able to make more accurate clinical judgments and guide caregivers to engage in more adaptive interactions with their child. These efforts will help to promote more successful recovery in children who have been sexually abused. 


\section{Acknowledgements}

The authors would like to extend their gratitude to Heidi M. Inderbitzen-Nolan, PhD, and Amber Ackerman for their assistance on an earlier version of this project.

\section{References}

Amato, 1991 P.R. Amato, The "child of divorce" as a person prototype: Bias in the recall of information about children in divorced families, Journal of Marriage and the Family 53 (1991), pp. 59-69.

Azar \& Wolfe, 1998 S.T. Azar and D.A. Wolfe, Child physical abuse and neglect. In: E.J. Mash and R.A. Barkley, Editors, Treatment of childhood disorders (2nd ed.), Guilford, New York (1998), pp. 501-544.

Ball et al., 1984 D.W. Ball, J.M. Newman and W.J. Scheuren, Teachers' generalized expectations of children of divorce, Psychological Reports 54 (1984), pp. 347-353.

Bauserman \& Rind, 1997 R. Bauserman and B. Rind, Psychological correlates of male child and adolescent sexual experiences with adults: A review of the nonclinical literature, Archives of Sexual Behavior 26 (1997), pp. 105141.

Briggs et al., 1995 K. Briggs, L. Hubbs-Tait, R.E. Culp and M. Blankemeyer, Perceiver bias in expectancies for sexually abused children, Family Relations 44 (1995), pp. 291-298.

Briggs et al., 1994 K. Briggs, L. Hubbs-Tait, R.E. Culp and A.S. Morse, Sexual abuse label: Adults' expectations for children, The American Journal of Family Therapy 22 (1994), pp. 304-314.

Bromfield et al., 1988 R. Bromfield, D. Bromfield and B. Weiss, Influence of the sexually abused label on perceptions of a child's failure, Journal of Educational Research 82 (1988), pp. 96-98.

Broussard et al., 1991 S. Broussard, W.G. Wagner and R. Kazelskis, Undergraduate students' perceptions of child sexual abuse: The impact of victim sex, perpetrator sex, respondent sex, and victim response, Journal of Family Violence 6 (1991), pp. 267-278.

Bryan \& Perlmutter, 1979 J. Bryan and B. Perlmutter, Immediate impressions of LD children by female adults, Learning Disability Quarterly 2 (1979), pp. 80-88.

Bryan et al., 1986 L.R. Bryan, M.M. Coleman, L.H. Ganong and S.H. Bryan, Person perception: Family structure as a cue for stereotyping, Journal of Marriage and the Family 48 (1986), pp. 169-174.

Bugental et al., 1998 D.B. Bugental, C. Johnston, M. New and J. Silvester, Measuring parental attributions: Conceptual and methodological issues, Journal of Family Psychology 12 (1998), pp. 459-480.

Burgoyne \& Hames, 2002 C.B. Burgoyne and R. Hames, View of marriage and divorce: An in-depth study of young adults from intact and divorced families, Journal of Divorce and Remarriage 37 (2002), pp. 75-100.

Cornell, 1989 D.G. Cornell, Adjustment and parent use of the term "gifted", Gifted Child Quarterly 33 (1989), pp. 59-64.

Cornell \& Grossberg, 1989 D.G. Cornell and I.N. Grossberg, Parent use of the term "gifted”: Correlates with family environment and child adjustment, Journal of the Education of the Gifted 12 (1989), pp. 218-230.

Darley \& Fazio, 1980 J.M. Darley and R.H. Fazio, Expectancy confirmation processes arising in the social interaction sequence, American Psychologist 35 (1980), pp. 867-881.

Deaux \& Major, 1987 K.K. Deaux and B. Major, Putting gender into context: An integrative model of gender-related behavior, Psychology Review 94 (1987), pp. 369-389.

Deblinger et al., 1996 E. Deblinger, J. Lippmann and R. Steer, Sexually abused children suffering posttraumatic stress symptoms: Initial treatment outcome findings, Child Maltreatment 1 (1996), pp. 310-321.

Demo \& Acock, 1996 D.H. Demo and A.C. Acock, Family structure, family process, and adolescent well-being, Journal of Research on Adolescence 6 (1996), pp. 457-488.

DeRoma et al., 1997 V.M. DeRoma, D.J. Hansen, A.C. Tishelman and P. D'Amico, Influence of information related to child physical abuse on professional ratings of adjustment and prognosis, Child Abuse and Neglect 21 (1997), pp. 295-308.

Dollar et al., 2004 K.M. Dollar, A.R. Perry, M.E. Fromuth and A.R. Holt, Influence of gender roles on perceptions of teacher/adolescent student sexual relations, Sex Roles 50 (2004), pp. 91-101. 
Feiring \& Lewis, 1993 C. Feiring and M. Lewis, Do mothers know their teenagers' friends? Implications for individuation in early adolescence, Journal of Youth and Adolescence 22 (1993), pp. 337-354.

Freund et al., 1979 J. Freund, R. Bradley and B. Caldwell, The home environment in the assessment of learning disabilities, Learning Disability Quarterly 2 (1979), pp. 39-51.

Fromuth et al., 2001 M.E. Fromuth, A. Holt and A.L. Parker, Factors affecting college students' perceptions of sexual relationships between high school students and teachers, Journal of Child Sexual Abuse 10 (2001), pp. $59-73$.

Gorey \& Leslie, 1997 K.M. Gorey and D.R. Leslie, The prevalence of child sexual abuse: Integrative review adjustment for potential response and measurement biases, Child Abuse and Neglect 21 (1997), pp. 391-398.

Guttman \& Broudo, 1989 J. Guttman and M. Broudo, The effect of children's family type on teachers' stereotypes, Journal of Divorce 12 (1989), pp. 315-328.

Hansen et al., 1998 D.J. Hansen, D.B. Hecht and K.T. Futa, Child sexual abuse. In: V.B. Van Hasselt and M. Hersen, Editors, Handbook of psychological treatment protocols for children and adolescents, Lawrence Erlbaum Associates, Hillsdale, NJ (1998), pp. 153-178.

Hetherton \& Beardsall, 1988 J. Hetherton and L. Beardsall, Decisions and attitudes concerning child sexual abuse: Does the gender of the perpetrator make a difference to child protection professionals?, Child Abuse E Neglect 22 (1988), pp. 1265-1283.

Holguin \& Hansen, 2003 G. Holguin and D.J. Hansen, The "sexually abuse child": Potential mechanisms of adverse influences of such a label, Aggression and Violent Behaviour 8 (2003), pp. 645-670.

Holm et al., 2002 J.W. Holm, G. Holguin and D.J. Hansen, Influences of the "sexual abuse" label on expectancies among professionals working with children: Implications for treatment and further research Poster session presented at the 35th annual meeting of the Association for Advancement of Behavior Therapy Reno, Nevada (2002, November).

Jumper, 1995 S.A. Jumper, A meta-analysis of the relationship of child sexual abuse to adult psychological adjustment, Child Abuse and Neglect 19 (1995), pp. 715-728.

Jussim \& Eccles, 1995 L. Jussim and J. Eccles, Naturalistic studies of interpersonal expectancies, Review of Personality and Social Psychology 15 (1995), pp. 74-108.

Kelley, 1995 P. Kelley, Developing healthy stepfamilies: Twenty families tell their stories, Haworth Press, New York (1995).

Kendall-Tackett \& Watson, 1991 K.A. Kendall-Tackett and M.W. Watson, Factors that influence professionals' perceptions of behavioral indicators of child sexual abuse, Journal of Interpersonal Violence 6 (1991), pp. 385395.

Langer \& Abelson, 1974 E.J. Langer and R.P. Abelson, A patient by any other name... Clinician group differences in labeling bias, Journal of Consulting and Clinical Psychology 42 (1974), pp. 4-9.

Maynard \& Wiederman, 1997 C. Maynard and M. Wiederman, Undergraduate students' perceptions of child sexual abuse: Effects of age, sex, and gender-role attitudes, Child Abuse E Neglect 21 (1997), pp. 833-844.

O’Donohue \& O'Hare, 1997 W. O'Donohue and E. O'Hare, The credibility of sexual abuse allegations: Child sexual abuse, adult rape, and sexual harassment, Journal of Psychopathology and Behavioral Assessment 19 (1997), pp. 273-279.

Podell et al., 1994 D.M. Podell, J. Kastner and S. Kastner, Mental retardation and women's perceptions of adolescent sexual abuse, Child Abuse and Neglect 18 (1994), pp. 809-819.

Rind \& Tromovitch, 1997 B. Rind and P. Tromovitch, A meta-analytic review of findings from national samples on psychological correlates of child sexual abuse, The Journal of Sex Research 34 (1997), pp. 237-255.

Rosenthal \& Jacobson, 1966 R. Rosenthal and L. Jacobson, Teachers' expectancies: Determinants of pupils' IQ gains, Psychological Reports 19 (1966), pp. 115-118.

Rosenthal \& Jacobson, 1968 R. Rosenthal and L. Jacobson, Pygmalion in the classroom, Holt, Rinehart, and Winston, New York (1968).

Rosenthal \& Rubin, 1978 R. Rosenthal and D.B. Rubin, Interpersonal expectancy effects: The first 345 studies, Behavioral and Brain Sciences 3 (1978), pp. 377-415.

Schwanenflugel et al., 1986 P.J. Schwanenflugel, M.E. Guth and D.F. Bjorklund, A developmental trend in the understanding of concept attribute importance, Child Development 57 (1986), pp. 421-430.

Smith et al., 1997 H.D. Smith, M.E. Fromuth and C.C. Morris, Effects of gender on perceptions of child sexual abuse, Journal of Child Sexual Abuse 6 (1997), pp. 51-63. 
Thornton, 1985 A. Thornton, Changing attitudes toward separation and divorce: Causes and consequences, American Journal of Sociology 90 (1985), pp. 856-872.

Touliatos \& Lindholm, 1974 J. Touliatos and B.W. Lindholm, Influence of parental expectancies and responsiveness on achievement motivation of minimally brain-injured and normal children, Psychological Reports 35 (1974), pp. 395-400.

United States Department of Health and Human Services, 2004 United States Department of Health and Human Services, Administration on Children, Youth, and Families, Child maltreatment 2002, U.S. Government Printing Office, Washington, DC (2004).

Vance \& Wallbrown, 1979 H.R. Vance and F. Wallbrown, Labeling of LD children and teacher perception, Academic Therapy 14 (1979), pp. 407-415.

Wagner et al., 1993 W.G. Wagner, R. Aucoin and J.T. Johnson, Psychologists' attitudes concerning child sexual abuse: The impact of sex of perpetrator, sex of victim, age of victim, and victim response, Journal of Child Sexual Abuse 2 (1993), pp. 61-74.

Waterman \& Kelly, 1993 J. Waterman and R.J. Kelly, Mediators of effects on children: What enhances optimal functioning and promotes healing?. In: J. Waterman, R.J. Kelly, M.K. Oliveri and J. McCord, Editors, Behind the playground walls: Sexual abuse in preschools, Guilford Press, New York (1993).

Zill, 1988 N. Zill, Behavior, achievement, and health problems among children in stepfamilies: Findings from a national survey of child health. In: E.M. Hetherington and J.D. Arasteh, Editors, Impact of divorce, single parenting, and stepparenting on children, Lawrence Erlbaum, Hillsdale, NJ (1988), pp. 325-368. 